\title{
The Sydney siege: courage, compassion and connectedness
}

\section{Recognising and responding with both our strengths and vulnerabilities to help get through times of distress}

\begin{abstract}
- he shock and threat of the Sydney siege on Monday 15 December $2014^{1}$ have provoked large-scale responses - to the emergency, its aftermath and the implications it may have for the future. The strong response by police, counterterrorism agencies and other experts and the leadership shown by civic agencies through the hours of uncertainty were watched by the world. There was powerful engagement, concern for outcomes and an outpouring of grief over the tragedy of the hostage deaths that occurred.

The more recent adverse events in Paris, still evolving as we write, ${ }^{2}$ speak to the growing environment of terror that the global community is facing. Over the coming months, doctors, and in particular general practitioners, have an important role in helping those who may be vulnerable.
\end{abstract}

\section{The siege}

All that was seen in the human responses to the Sydney siege speaks of the compassion, courage, commitment, care and concern for others among the multitude who engaged with the attack and its consequences. The tributes and memorials of flowers attest to how deeply people were moved, and continue to be. People identify with suffering and loss, with threat and survival, with grief and anger - reflecting strengths as well as empathy. ${ }^{3}$ For some, the experience of the siege will continue and reverberate; their distress may fluctuate or continue unabated.

Elements of resilience are critical in surviving and getting through such threats. One of these elements is the value that comes from connectedness to others. There is social capital in the coming together of people and communities. ${ }^{4,5}$ The support of networks, including social media, is increasingly important in disasters and other emergencies. The \#illridewithyou hashtag is an example of a show of support from strangers that builds strength. In their hearts, people yearn for the kindness of others and the possibility of a safe world where we all belong, and social media provides an opportunity to express and emphasise our shared values.

Such acts of kindness from strangers help create a sense of safety during uncertainty. People can support those affected by acknowledging what has happened and by offering help, shelter, safety and comfort. Figuratively, and at times literally, people put their arms around those who are distressed. These natural strengths and

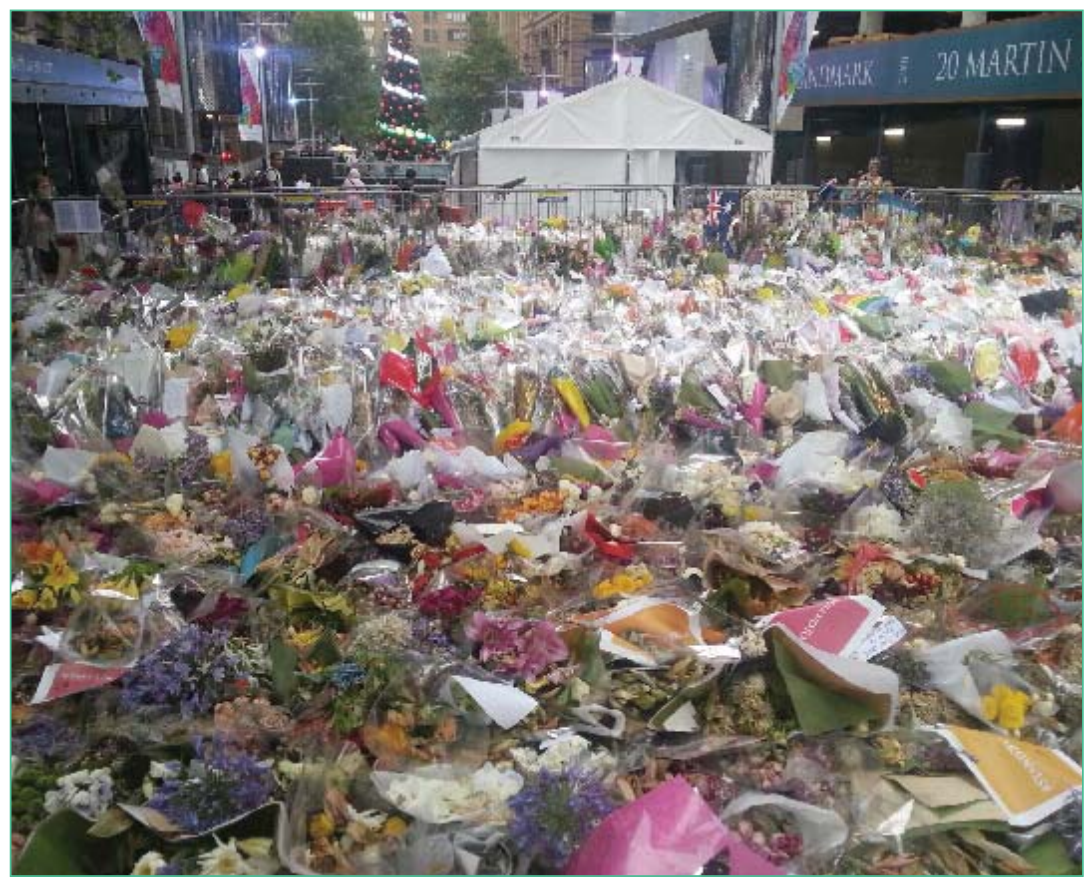

resilience are important resources for people during and after this emergency.

Altruism is a natural response in times of need. This has previously been exemplified by those who tried to rescue strangers after the Bali bombings and those who helped people descend the stairwells in the 9/11 terrorist attacks.

\section{The aftermath}

With the siege come many questions and uncertainties - the search to make meaning and to understand how this could happen. This phase of questioning can be very complex.

In circumstances where something has gone so wrong, there is, alongside the realities of complex human behaviour and beliefs, a strong demand to find fault. This is a time of building knowledge about threat and safety. The challenge lies in identifying what can be done to prevent and protect against further attack, yet still support the freedoms of a valued societal framework.

1 Australian National University, Canberra, ACT. 2 University of Western Sydney, Sydney, NSW. b.raphael@uws.edu.au

The backwards and forwards of regret and hope are the "normal" of who we are, and how we hold our own realities, strengths and specific fears. Not wanting to give up what might have been, we swing between the imagined hope that we could change what has happened and the reality of the need to move forward. 
The challenges in the aftermath of such an event lie in recognising and responding with both our strengths and vulnerabilities. Courage, compassion and connection with others are powerful resources held by us all., ${ }^{67}$ The affectional bonds, the "love actually", will help us protect and care for the young, the old, the injured, the vulnerable. As Ben Borgia, victim of the 2002 Bali bombings, put it, "The opportunity to be guided by good and giving people has me engaged in life again". ${ }^{8}$

There is also a "dark side" that may follow such events, with the realisation that some individuals have both the capacity to hate and the desire for revenge. For some people, an overwhelming sense of threat and loss may bring feelings of helplessness. The images of people of all cultures and faiths presenting floral tributes after the siege can help to combat this by enhancing the positive emotions of connectedness and sense of safety.

GPs play an important role in helping patients throughout such incidents ${ }^{9}$ and through the reawakening of previous vulnerabilities. Individuals respond in their own ways to threatening situations, whether exposed directly to the danger or as indirect observers. Many of those overwhelmed by their feelings may benefit from education on "what reactions are normal", as reported after the 2009 Black Saturday bushfires in Victoria (Ruth Wraith, Disaster Consultant and Child Psychotherapist, Victoria, personal communication).

It is important for GPs responding to the needs of their patients to recognise patterns of distress, which may present in many ways, from insomnia, profound fatigue, anger, anxiety or depression to exacerbations of pre-existing mental or physical health problems. Those patients who show continued fear, anxiety or other prolonged distress may need specialised assessment to regain a sense of safety.

Recent studies on the physical effects of disasters have highlighted the need to consider the emergence of new physical conditions. Diagnoses of stress-induced cardiomyopathy after the 2011 Queensland floods ${ }^{10}$ remind us that, alongside support for mental health conditions, surveillance for physical conditions is important. After the 9/11 terrorist attacks, a study of 2729 adults demonstrated that acute stress responses to the attack were associated with a 53\% increased incidence of cardiovascular conditions over the following 3 years. ${ }^{11}$

All professionals involved in the management of and response to such events should be aware of the need for a health check for physical or mental health symptoms that develop. Excellent clinical resources exist to help assess any mental health needs both immediately and over time, and to provide important interventions as appropriate. ${ }^{12}$

For children, signs of distress vary with age and include behavioural change, such as withdrawal, acting out, fearfulness, clinginess or regression, and physical presentations such as abdominal pain. Specifically, children need protection from undue exposure to the media. Simple explanations, reassurance and affectionate bonds through comfort and holding all demonstrate to children that their world is still safe. Extensive resources are available from the Australian Child and Adolescent Trauma, Loss and Grief Network (http://earlytraumagrief.anu.edu.au).

\section{The future}

The backwards and forwards of regret and hope are the "normal" of who we are
We acknowledge that terrorism has more threatening implications than a natural disaster because of the malevolent intent, which results in a greater effect in the aftermath and uncertainty about future attacks. ${ }^{13}$ Consequently, terrorism events tend to have a greater effect on the health of individuals. ${ }^{14}$ Caring for people who have been affected by terrorism requires sensitive and skilled management. Dunsmore, a clinician with extensive experience in dealing with victims of terrorism, highlights "the shattering of people's views of their world, the randomness, and the loss of the sense of safety and trust" (Julie Dunsmore, Senior Psychologist, Bali Trauma Recovery Program, NSW Health, personal communication). She emphasises the importance of human engagement and understanding the context of people's lives, the impact of the many losses and the need to regain a sense of safety and trust. Survivors and the bereaved have stressed the importance of continuing support, in particular the community staying with them for the long haul and through difficult times such as anniversaries and other reminders.

What is critical is our strength as people, the strength of our nation and our commitment to others beyond our shores. The Australian Government provides resources on protecting our communities and ourselves. ${ }^{15}$

We may - as individuals, as families, as communities - face many challenges in tough times, but we do not give up. We endure, we struggle, we fail, we succeed, we go forward to the "new normal" and, as best we can, we look after one another, the stranger, in the face of threat and adversity.

As Australians we will stand up against threat, conflict and injustice and we will try to do our best. We will look to the future with strength and hope. As our Indigenous people, the oldest surviving culture, so wisely say:

... our strength is that we "have survived" ...

We depend on each other, we understand and support each other. ${ }^{16}$

Acknowledgements: We acknowledge all those who have contributed to our knowledge about disasters over the past 40 years since Cyclone Tracy.

Competing interests: No relevant disclosures.

Provenance: Commissioned; not externally peer reviewed. 
1 Sydney siege. The Guardian Dec 2014 - Jan 2015. http://www. theguardian.com/australia-news/sydney-siege (accessed Jan 2015).

2 Charlie Hebdo attack. The Guardian Jan 2015. http://www. theguardian.com/world/charlie-hebdo-attack (accessed Jan 2015).

3 Raphael B. Foreword. In: Neria Y, Gross R, Marsh R, Susser E, editors. 9/11: Mental health in the wake of terrorist attacks. Cambridge: Cambridge University Press, 2006: xxvi-xxviii.

4 Norris FH, Stevens SP, Pfefferbaum B, et al. Community resilience as a metaphor, theory, set of capacities, and strategy for disaster readiness. Am J Community Psychol 2008; 41: 127-150.

5 Taylor M, Wells G, Howell G, Raphael B. The role of social media as psychological first aid as a support to community resilience building. AJEM 2012; 27 (1): 20-26.

6 Raphael B. Resilience and self care for principals and teachers. Canberra: Australian Child and Adolescent Trauma, Loss and Grief Network, 2010. http://earlytraumagrief.anu. edu.au/files/ACATLGN_Raphael_ResilienceSelfCare_D1_0.pdf (accessed Jan 2015).

7 Raphael B, Ma H. Mass catastrophe and disaster psychiatry. Mol Psychiatry 2011; 16: 247-251.

8 United Nations. Supporting victims of terrorism. UN, 2009: 18. http://www.un.org/en/terrorism/ctitf/pdfs/un_report_ supporting_victims_terrorism.pdf (accessed Jan 2015).

9 Burns PL, Aitken PJ, Raphael B. Where are general practitioners when disaster strikes? Med J Aust 2015. In press.
10 Butterly SJ, Indrajith M, Garrahy P, et al. Stress-induced takotsubo cardiomyopathy in survivors of the 2011 Queensland floods. Med J Aust 2013; 198: 109-110.

1 Holman EA, Silver RC, Poulin M, et al. Terrorism, acute stress, and cardiovascular health: a 3-year national study following the September 1lth attacks. Arch Gen Psychiatry 2008; 65: 73-80.

12 NSW Health. Mental health impacts. http://www.health.nsw. gov.au/emergency_preparedness/mental/Pages/default. aspx (accessed Jan 2015).

13 Ursano RJ, Fullerton CS, Weisaeth L, Raphael B. Individual and community responses to disasters. In: Ursano RJ, Fullerton CS, Weisaeth L, Raphael B, editors. Textbook of disaster psychiatry. Cambridge: Cambridge University Press, 2007: 6.

14 Stevens GJ, Dunsmore JC, Agho KE, et al. Long-term health and wellbeing of people affected by the 2002 Bali bombing. Med J Aust 2013; 198: 273-277.

15 Australian Government. Australian national security. Publications. http://www.nationalsecurity.gov.au/ Mediaandpublications/Publications/Pages/dafault.aspx (accessed Jan 2015).

16 Central Australian Aboriginal Congress and Anyinginyi Congress Aboriginal Corporation. Joint submission on human rights issues relating to Aboriginal people with mental illness in Central Australia. Canberra: Parliament of Australia, 1992: 4. http://www.aph.gov.au/ /media/wopapub/senate/ committee/mentalhealth_ctte/submissions/sub486_ attachl_pdf.ashx (accessed Jan 2015). 